\title{
Uma Análise da Emergência de Pensamento Computacional em Práticas de Desenvolvimento de Jogos Digitais na Educação do Campo
}

\author{
Rozelma França \\ Departamento de \\ Educação \\ UFRPE \\ Recife, PE, Brasil \\ rozelma.franca@ufrpe.br
}

\author{
Taciana Pontual \\ Departamento de \\ Computação \\ UFRPE \\ Recife, PE, Brasil \\ taciana.pontual@ufrpe.br
}

\author{
Flávia Peres \\ Departamento de \\ Educação \\ UFRPE \\ Recife, PE, Brasil \\ peres.flavia@gmail.com
}

\author{
Dyego Morais \\ Centro de \\ Informática \\ UFPE \\ Recife, PE, Brasil \\ dyego12345@gmail.com
}

\begin{abstract}
RESUMO
Embora o Pensamento Computacional (PC) seja um tema cada mais vai pesquisado no contexto da educação básica, ainda são poucos os trabalhos que fazem essa investigação no contexto da Educação do Campo. Nela, há diretrizes específicas que favorecem a mediação social, mas, no geral, suas tecnologias digitais educacionais ainda são produzidas em grandes centros urbanos, descontextualizadas dos conteúdos curriculares para territórios rurais. Nesse contexto, o presente artigo analisa a emergência do PC em diferentes fases de um processo de desenvolvimento de jogos digitais em uma escola do campo no nordeste brasileiro. Este processo ancora-se em uma abordagem histórico-cultural e organiza-se como uma comunidade de prática, envolvendo pesquisadores, estudantes, professoras e técnicos agrícolas em interações horizontais e construção coletiva de saberes. O PC emerge na concepção das narrativas e implementação dos jogos, privilegiando perspectivas situada e crítica em que a computação se torna ferramenta de expressão, questionamento e desejo de transformação do contexto socioeconômico dos povos campesinos.
\end{abstract}

\section{PALAVRAS-CHAVE}

Pensamento Computacional, Educação do Campo.

\section{Introdução}

A Educação do Campo, como proposta contra-hegemônica para a educação ofertada em territórios rurais, vem ganhando mais força com o estabelecimento de diretrizes que se contrapõem ao paradigma de supervalorização da urbanidade, de antigas escolas rurais, cujos fundamentos e práticas ocorriam desvinculados das condições de vida dos sujeitos do campo [16]. Em se tratando de Educação do Campo, como define Caldart [16], o povo tem direito

\footnotetext{
Fica permitido ao(s) autor(es) ou a terceiros a reprodução ou distribuição, em parte ou no todo, do material extraído dessa obra, de forma verbatim, adaptada ou remixada, bem como a criação ou produção a partir do conteúdo dessa obra, para fins não comerciais, desde que sejam atribuídos os devidos créditos à criação original, sob os termos da licença CC BY-NC 4.0.

EduComp'21, Abril 27-30, 2021, Jataí, Goiás, Brasil (On-line)

(C)2021 Copyright mantido pelo(s) autor(es). Direitos de publicação licenciados à Sociedade Brasileira de Computação (SBC).
}

a uma educação pensada desde o seu lugar e com sua participação, vinculada à cultura em que está situado e suas necessidades. Mas nem todas as práticas em territórios rurais respeitam os preceitos de transformação social que caracterizam a educação do campo, reproduzindo práticas amparadas por um modelo hegemônico, que acaba por invisibilizar os povos do campo e acentuar as desigualdades sociais.

Pensar o campo como território é concebê-lo como local onde se realizam as diversas formas de organização do campesinato e da agricultura, e compreendê-lo como espaço onde as múltiplas dimensões da vida acontecem [4], em relação estreita com os conhecimentos de um povo. As práticas educativas nesses territórios são favorecidas em "escolas com um projeto político pedagógico vinculado às causas, aos desafios, aos sonhos, à história e à cultura do povo trabalhador do campo" [16]. Essa educação deve respeitar as raízes dos povos do campo e ter como base a formação humana integral e crítica, com vistas a um novo desenvolvimento do campo e da sociedade, numa perspectiva libertadora [6].

No entanto, percebe-se que nos contextos rurais ainda há marcas de desarticulação entre o saber mediado na escola e a realidade dos povos que vivem no campo, criando barreiras para produções de sentido sobre os contextos camponeses e disseminando significados de uma educação centrada em temáticas urbanas.

Muitas discussões sobre educação destinada à população rural atentam, entre outros aspectos, para a especificidade da relação campo-cidade [13] e para a complexidade da operacionalização da oferta de educação nas zonas rurais, destacando-se o desafio da produção de materiais didáticos alinhados às diretrizes da educação do campo.

O projeto DEMULTS-Campo se insere neste contexto propondo uma comunidade de prática formada por estudantes e professoras de escolas do campo, técnicos em agroecologia e pesquisadores acadêmicos, com o objetivo de desenvolver artefatos digitais educacionais que possam ajudar a suprir a lacuna dos materiais didáticos contextualizados e fundamentados nas questões da educação do campo.

Neste processo, a troca de saberes entre os membros da comunidade envolve a aprendizagem e aprofundamento sobre as temáticas campesinas, associadas à apropriação de técnicas e 
conceitos da computação para desenvolver artefatos significativos e contextualizados. Neste artigo, a análise centra-se sobre jogos digitais educacionais desenvolvidos em uma experiência com escolas do campo de Pernambuco, sob uma perspectiva situada e crítica, buscando responder à seguinte pergunta:

- Como práticas de pensamento computacional emergem no processo de desenvolvimento de jogos digitais educacionais com a participação de estudantes de escolas do campo?

Assim, o restante deste trabalho encontra-se organizado da seguinte forma: na Seção 2 o PC é conceituado, sendo também apresentados trabalhos que buscaram sua promoção do contexto da educação do campo; na Seção 3 são apresentadas as etapas do DEMULTS-Campo, perpassando os métodos de coleta e análise dos dados. Os resultados da pesquisa são apresentados e discutidos na Seção 4 e, na Seção 5, são tecidas algumas considerações finais e pretensões de trabalhos futuros decorrentes desta pesquisa.

\section{Fundamentação Teórica e Trabalhos Relacionados}

Nesta seção o pensamento computacional é definido sob diferentes perspectivas teóricas, e estudos de sua aplicação em contextos rurais também são reportados.

\subsection{Pensamento Computacional}

Já na década de 1970 Seymour Papert propunha o uso do computador como ferramenta para a aprendizagem, pela modelagem de ideias com a linguagem Logo [18]. A partir do aumento do interesse pela exploração de conceitos e fundamentos da Ciência computação na educação básica, remontado principalmente a 2006 com um artigo de Jeannette Wing [11], a temática ganhou um novo enfoque, sendo comumente referenciada pelo termo pensamento computacional.

Embora o termo tenha diversas definições [15], pode-se considerar que ele é pautado em quatro pilares principais, derivados de fundamentos da computação: decomposição, reconhecimento de padrões, abstração e algoritmos [2]. Nesse sentido, o pensamento computacional favorece o processo de resolução de problemas a partir de sua divisão em partes menores e mais gerenciáveis (decomposição). Cada um desses problemas menores pode ser analisado e resolvido, considerando como problemas similares foram solucionados anteriormente (reconhecimento de padrões), focando nos elementos importantes e ignorando aqueles irrelevantes para o contexto em questão (abstração). A partir disso, as etapas para a resolução do problema são projetadas em formato de sequências de instruções (algoritmos), as quais, se convertidas para uma linguagem adequada, poderão ser usadas para programar um computador.

Embora tal visão do PC seja muito disseminada nos meios científicos e acadêmicos, pesquisas contemporâneas têm ampliado as discussões, propondo diferentes perspectivas para se compreender e trabalhar com PC. Nesse contexto, Kafai et al. [19] organizam o espaço teórico do PC sob três ênfases: cognitiva, situada e crítica. A cognitiva fornece aos estudantes uma compreensão dos principais conceitos e práticas computacionais, ressaltando, assim, a construção de habilidades e competências que serão úteis na universidade e futuras carreiras. De acordo com Brennan \& Resnick [12], os conceitos computacionais são aprendidos com o ato de programar (exemplos: condicionais, repetição); e as práticas computacionais são desenvolvidas à medida que os aprendizes se envolvem com os conceitos, como depurar projetos ou integrar trechos ou funcionalidades de projetos desenvolvidos por outras pessoas.

Embora tais habilidades possam ser desenvolvidas sob diferentes abordagens, Kafai et al. [19] consideram que na ênfase cognitiva a resolução de problemas é realizada por estudantes individualmente, tais como as pesquisas para a introdução da programação realizada na década de 1980.

Já a situada [19] é uma alternativa à ênfase cognitiva e reconhece a necessidade de perspectivas de aprendizagem autênticas e a compreensão de que aprender é sobre se tornar um membro de uma comunidade de prática com objetivos e valores. Brennan e Resnick [12] apresentam as perspectivas computacionais como relacionadas ao contexto em que os estudantes estão inseridos, incluindo expressar-se, questionar e colaborar com outras pessoas.

Por fim, a ênfase crítica [19], que surgiu mais recentemente, alinhada à pedagogia crítica, vê a computação como um potencial canal para envolver os estudantes em desafios, políticos e morais, por exemplo, por meio da produção de mídias digitais. Tissenbaum et al. [14] propõem um movimento de transição do pensamento computacional para a "ação computacional", criando oportunidades para que a computação tenha impacto direto nas comunidades, por meio do desenvolvimento de soluções para necessidades reais dos envolvidos. Os autores trabalham com os conceitos de "identidade computacional", que se refere ao reconhecimento das pessoas de que elas têm capacidade de desenvolver soluções tecnológicas; e "empoderamento digital", que se refere à habilidade de engajar-se criticamente nas questões da comunidade e da vida, agindo de maneira significativa. Raabe et al. [1] também refletem sobre essas questões ao discutirem abordagens de computação na educação básica, destacando a necessidade do seu uso para garantir equidade e diversidade de oportunidade para participação cidadã.

Entendemos que essas perspectivas sobre a compreensão e aplicação de PC carregam, em suas bases, concepções implícitas sobre como os sujeitos aprendem e, nesta direção, impactam sobre as práticas educacionais possíveis e os consequentes alcances na aprendizagem e no desenvolvimento dos estudantes. A perspectiva cognitiva, por exemplo, distancia-se de um fundamento históricocultural, ao não dar margens ao argumento da constituição social dos processos cognitivos, não se abrindo, assim, à necessária compreensão das situações práticas para emergência do $\mathrm{PC}$ como atrelada aos contextos interacionais dessa emergência. Em outro polo, as perspectivas situada e crítica abrem-se aos aspectos da experiência prática, no processo de resolução de problemas, favorecendo metodologias e didáticas para uma integração das discussões sobre PC na Educação do Campo, alinhando-se coerentemente às suas diretrizes. 
A Emergência de Pensamento Computacional em Práticas de Desenvolvimento de Jogos Digitais na Educação do Campo

Nesse contexto, o sentido do trabalho do povo camponês e das lutas sociais e culturais que buscam garantir a sobrevivência a partir desse trabalho, na Educação do Campo, podem se ancorar nas perspectivas situada e crítica do pensamento computacional, enfatizando a função social da escola e da computação nos processos de transformação social.

\subsection{Pensamento Computacional na Educação do Campo}

Ainda são poucos os trabalhos que investigam o pensamento computacional no contexto da Educação do Campo. A seguir são brevemente relatados aqueles encontrados no Google Scholar e ACM Digital Library que trazem em seu título elementos associados à temática.

Considerando que a produção de conhecimento nas escolas não deve ser desvinculada da realidade dos sujeitos, Vieira e Sabbatini [17] se propuseram a investigar como a utilização do Scratch pode contribuir na promoção do pensamento computacional de estudantes do $5^{\circ}$ ano de uma escola do campo de Pernambuco. $\mathrm{Na}$ experiência, os estudantes se envolveram na programação de um projeto com a temática "lixo e meio ambiente", propondo alternativas de soluções para reduzir a produção de lixo e seu reaproveitamento. Os resultados do estudo se detêm, especialmente, à percepção dos estudantes quanto ao uso do Scratch, não havendo uma discussão quanto à perspectiva de pensamento computacional que poderia ser enfatizada nessa prática.

Dillon e Anderson-Herzog [7], observando que ações para o aumento da representatividade de minorias em Ciência da Computação têm sido realizadas com mais frequência em áreas urbanas, direcionaram seus esforços a jovens afro-americanos de uma escola rural nos Estados Unidos. Ao expor esses estudantes à programação, buscaram incentivá-los e encorajá-los a ver a Ciência da Computação como uma possível escolha de carreira; tendo, ao final, quase metade dos estudantes demonstrado algum nível de interesse pela área.

Fasy et al. [5] propuseram atividades para estudantes rurais, incluindo indígenas, nos Estados Unidos, buscando ampliar o acesso à Ciência da Computação. Nelas, os estudantes deveriam articular a definição de um algoritmo na criação de histórias animadas na ferramenta de programação Alice, baseadas nas comunidades em que vivem. Esperava-se que eles reconhecessem o pensamento computacional como uma parte importante da resolução de problemas de Ciência da Computação. Como resultado, em geral, os autores perceberam que os estudantes gostaram de usar o Alice, desejavam criar novas histórias com tal ambiente e tiveram um interesse maior pela área de computação após as atividades.

Embora esses trabalhos sejam ilustrativos para as tentativas de relacionar educação em territórios rurais e pensamento computacional, eles parecem aderir a uma concepção de PC desvinculada das condições materiais de sua emergência. Assim, pressupõem que o desenvolvimento cognitivo de habilidades e competências, em si mesmo, favoreceria os povos do campo. Porém, em polo diverso, com base em uma abordagem histórico-
EduComp’21, Abril 27-30, 2021, Jataí, Goiás, Brasil (On-line)

cultural em psicologia e educação, é possível afirmar que, somente se as práticas educativas para emergência do PC forem convergentes com os significados do modo de vida camponês, é que poderiam favorecer um desenvolvimento do PC para produção de sentidos e resolução de problemas nos contextos rurais. Sendo o pensamento mediado linguisticamente e marcado por aspectos subjetivos, no caso de territórios do campo, as práticas para emergência do PC deveriam estar alinhadas à luta contrahegemônica e às diretrizes da educação do campo. Com essa abordagem, podemos vislumbrar no presente estudo um jogo dialético em que tanto a educação do campo pode ser favorecida pelos estudos sobre PC, quanto os estudos sobre PC podem ser favorecidos pelas práticas educativas do campo.

\section{O DEMULTS-Campo}

O DEMULTS (Desenvolvimento Educacional de Multimídias Sustentáveis) caracteriza-se como uma pesquisa-ação, em que os pesquisadores realizam ações nos contextos escolares que, no caso do DEMULTS-Campo, são escolas situadas na zona rural. No ciclo aqui apresentado, essas ações conjuntas dos pesquisadores envolveram estudantes do ensino fundamental II e profissionais que trabalham em duas escolas (professoras e técnicos em agroecologia), na zona rural de Vicência-PE, as quais seguem as diretrizes da educação do campo, coordenadas pela secretaria de educação do município.

Vale ressaltar que houve o consentimento dos pais/responsáveis dos estudantes, com assinatura de termo, para participação na pesquisa. Um deles era maior de 18 anos, então assinou o próprio Termo de Consentimento Livre e Esclarecido.

Organizadas como uma Comunidade de Prática $(\mathrm{CoP})$, as situações interativas promovidas nos encontros do DEMULTS buscam providenciar um modelo participativo ao processo de ensino-aprendizagem escolar. Lave e Wenger [10] definem uma Comunidade de Prática como um grupo de pessoas que visa desenvolver habilidades em torno de um interesse em comum, compartilhando práticas, negociando significados, identidades e culturas, formando assim um sistema de aprendizagem social [8]. A interação entre sujeitos, que se encontram em níveis diversos de conhecimento sobre determinado aspecto da prática (experts e novatos), vai favorecer uma participação periférica legítima, em que aos poucos percebe-se a migração dos sujeitos, de regiões mais periféricas na $\mathrm{CoP}$, até o centro do processo. Nessa participação, destaca-se a apropriação de significados específicos à situação, e produção de sentidos, com impacto nas identidades dos sujeitos.

A equipe de pesquisa contou com a presença constante de 5 pesquisadores. Deles, dois pesquisadores ficaram responsáveis pela programação, de acordo com sua expertise, duas pesquisadoras responsáveis pelos processos de aprendizagem, propriamente ditos, pela expertise em pedagogia e psicologia, e uma pesquisadora responsável pelo design gráfico de interface dos artefatos que estavam sendo desenvolvidos. Houve a participação efetiva de três técnicos agrícolas que atuam na cidade de Vicência-PE, nas escolas do campo, além de alguns profissionais da educação que atuam nas 
duas escolas e nos auxiliaram com o conhecimento e a vivência sobre e no campo, como constará nas análises.

\subsection{Etapas do DEMULTS-Campo}

Com as experiências advindas dos ciclos anteriores, a metodologia DEMULTS foi sendo transformada, por estar em constante aprimoramento, no diálogo com os estudantes em seus territórios e as demandas dos novos contextos para a sua aplicação. As etapas da metodologia DEMULTS seguidas no ciclo a que se refere este artigo foram: Convite e Apresentação, Imersão, Delimitação Conceitual, Ideação, Produção e Testes (Figura 1).

Convite e Apresentação - A seleção dos estudantes ocorreu a partir de um convite realizado pela coordenação das próprias escolas para estudantes com perfis diversos, com foco na pluralidade de perfis dos indivíduos participantes. A proposta foi explicada desde seus objetivos e temática até as informações mais técnicas, como o cronograma. Realizou-se o levantamento das expectativas e dúvidas acerca de sua realização. Ainda nesta etapa, os/as estudantes selecionados trouxeram, a partir de uma dinâmica em grupo de criação de desenhos, sua concepção do que seriam tecnologias, tecnologias digitais e seus usos cotidianos.

Imersão - Nesta etapa, objetivou-se compreender mais sobre o cotidiano e os problemas do contexto dos estudantes, em seus territórios, e orientar para uma reflexão sobre suas vivências como cidadãs/os. Com base nos vários interesses obtidos com os relatos individuais, foram formados subgrupos, para registro de uma atividade cotidiana. Para tal, utilizou-se a estrutura das histórias em quadrinhos, que possui bastante semelhança com o formato dos storyboards que, posteriormente, serão refinados para o processo de criação dos jogos digitais.

Delimitação Conceitual — Nesta etapa, os/as pesquisadores/as buscaram um maior conhecimento sobre o contexto de vivência da comunidade escolar, provocando reflexões e diálogos com os estudantes, a respeito de seus interesses comuns e quais os possíveis problemas comunitários que caracterizam seus cotidianos do campo. Este momento deu-se entre a etapa da imersão e a da ideação, ganhando relevância por ser o momento em que foi definida a temática do artefato digital educacional. A partir dos problemas e situações cotidianas identificados na imersão, partiuse para uma integração entre os conhecimentos prévios dos estudantes, muito relacionados ao seu cotidiano no campo, com os conteúdos científicos e curriculares que podem ser abordados nos artefatos.

Ideação - Os problemas cotidianos levantados, na etapa da delimitação conceitual foram organizados em categorias, gerando tópicos que formaram a base temática dos artefatos digitais a serem desenvolvidos. Ainda na etapa de imersão, percebeu-se na CoP a necessidade da participação de especialistas nos temas apontados, os quais abordariam diretamente conteúdos sobre vida no campo, agricultura, e ecologia. Essa necessidade foi sanada com a participação contínua dos técnicos agrícolas que já realizam atividades sistemáticas formalizadas nas escolas em foco. $\mathrm{O}$ debate rural-urbano e a ênfase em conteúdos que dialogam com os territórios do campo foram ganhando contornos específicos, com os conhecimentos dos técnicos, que integram discussões sobre cidadania e sustentabilidade, entrelaçadas com agricultura familiar e agroecologia. Os estudantes fizeram escolhas sobre os artefatos digitais que seriam desenvolvidos, realizaram esboços, roteiros e storyboards que apontavam a preferência pelo desenvolvimento de jogos digitais, havendo também o interesse pelo desenvolvimento de um aplicativo.

Produção - Nesta etapa, objetiva-se a prototipação dos jogos e aplicativos digitais educacionais direcionados a um público do qual os estudantes também fazem parte. Para os grupos que iriam construir jogos, foi apresentado o software Scratch e, para o grupo que iria elaborar um aplicativo, foi apresentado o software MIT App Inventor. Suas funcionalidades foram sendo aprendidas no decorrer do processo de produção, sem delimitação de um período específico para aulas. Não foram realizados encontros específicos sobre pensamento computacional ou programação. Após a apresentação de algumas possibilidades oferecidas pelos softwares, as/os estudantes foram incentivadas/os a encontrar soluções para materializar digitalmente as ideias tidas e registradas anteriormente no papel. Como não se tem aulas, a interação entre experts e novatos nessa etapa é essencial para o desenvolvimento dos artefatos, bem como para a aprendizagem dos conceitos de programação, design e agroecologia. Durante a etapa de produção, comumente há retornos à etapa de ideação para ajustes nas narrativas ou fluxos de interação dos artefatos.

Testes — De acordo com a metodologia do DEMULTS, os estudantes devem testar os protótipos com outras pessoas (tipicamente estudantes de outras turmas) que não participam do projeto. A etapa de testes permite aos estudantes apresentarem suas ideias e produções e ao mesmo tempo perceberem pontos de melhoria nos artefatos. Entretanto, o ciclo em questão foi interrompido ao final da etapa de produção pela pandemia da COVID-19, deixando esta etapa suspensa.

Nas três últimas etapas, há um movimento sistêmico com retornos constantes entre elas. Desse modo, quando necessário, o artefato passa por mudanças processuais envolvendo ideação, produção e testes, até atingir o resultado esperado pelo grupo de estudantes, com mediação dos pesquisadores. Busca-se uma relação de horizontalidade entre os pesquisadores e os estudantes, em trocas de gestos, discursos, registros e compreensões sobre os artefatos que configuram um contexto de muita aprendizagem em programação, design e agroecologia. 


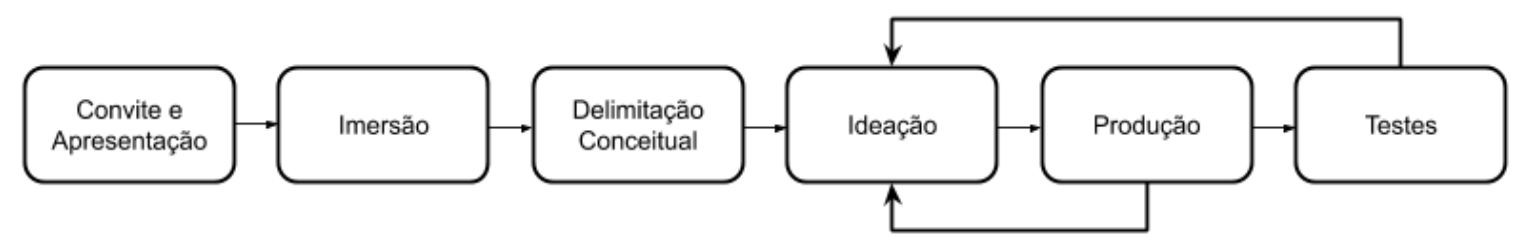

Figura 1: Etapas do DEMULTS-Campo. Fonte: Arquivos da Pesquisa

\subsection{Coleta e Análise de Dados}

Durante esses processos metodológicos para o desenvolvimento dos artefatos digitais, orientados pela etnografia, utilizamos como ferramentas para a coleta de dados:

- Diário de campo - foram feitos registros de duas formas: anotações a partir de observação participante, durante as atividades; e gravações em áudio logo após o encerramento das atividades do dia, em que os pesquisadores envolvidos reuniam-se para narrar livremente suas impressões sobre o encontro, destacando sem restrições os episódios e aspectos que lhe vinham à mente, e revezando-se nas falas até que os assuntos se esgotassem;

- Entrevistas estruturadas e semiestruturadas com os sujeitos participantes;

- Videografias e fotografias como registros imagéticos dos momentos durante os encontros;

- Desenhos e registros gráficos feitos pelos estudantes.

Os resultados apresentados neste artigo referem-se a dados oriundos de fotos e episódios videográficos dos estudantes realizando as atividades, e dos desenhos da fase de ideação; tendo o pensamento computacional como unidade de análise.

O processo de análise dos desenhos pautou-se em Pires et al. [9], ao buscar identificar a emergência de estruturas lógicas em narrativas infantis. Nesta pesquisa, o processo de construção de storyboards se configura um elemento importante para o desenvolvimento dos artefatos digitais, e permite explorar singularidades do PC, mesmo nas primeiras etapas da metodologia DEMULTS.

Em relação aos vídeos, foi utilizada a análise interacional [3]. Esse método possibilita analisar como as pessoas interagem com outras pessoas e com objetos em situações específicas; e dialoga com a perspectiva histórico-cultural, subjacente à concepção de cognição situada e distribuída, adotada nesta pesquisa. Nesse sentido, os dados básicos que teorizam o conhecimento e prática do PC se fundamentam nos detalhes das interações sociais que ocorrem entre os membros da comunidade de prática.

$\mathrm{Na}$ transcrição dos episódios videográficos foi privilegiada a representação da fala dos participantes, como também comportamentos não verbais, como mudanças na posição corporal e manipulação de objetos; complementando a comunicação verbal. Em relação aos sinais mais frequentemente usados, estão listados no Quadro 1. A identidade dos participantes foi preservada, sendo usada somente a letra inicial de seus nomes em maiúscula.

\begin{tabular}{l|l}
\hline Sinal & Significado \\
\hline MAIÚSCULA & Enfase \\
\hline$[[$ & Falas simultâneas \\
\hline$::$ & Alongamento de vogal \\
\hline$((\quad))$ & Atividade do sujeito \\
\hline$/ . . /$ & Corte na transcrição \\
\hline
\end{tabular}

Quadro 1: Sinais usados nas transcrições

\section{Resultados e Discussões}

As duas escolas em que foi realizado o ciclo aqui analisado ficam localizadas no município de Vicência, Zona da Mata Norte de Pernambuco. A cidade de Vicência tem vínculo histórico com o corte de cana-de-açúcar, de modo que o seu caule faz parte do brasão da cidade e até hoje a cidade é circundada por terrenos de plantio do caule. As escolas participantes deste ciclo situam-se dentro de terrenos de usinas de cana-de-açúcar (uma desativada e outra ativada). Entender tal vínculo se faz importante para as análises e resultados apresentados a seguir.

Em relação ao contato prévio dos estudantes com tecnologias, foi feito um braindraw no início do processo. Nele, os estudantes desenharam colaborativamente tecnologias que tinham contato no cotidiano. Apareceram majoritariamente smartphones e computadores; provavelmente devido à informação prévia sobre o projeto, mas também houve ocorrência de desenhos de tratores e TVs. Ao longo do processo, há dados que evidenciam: dificuldade de manusear o mouse, interagir com buscadores (como o Google), dificuldade de interpretação de texto, facilidade de manusear o celular para acessar e consumir multimídias de entretenimento (através do YouTube) e para se comunicar entre eles (através do WhatsApp), bem como para jogar online (FreeFire).

\subsection{A Emergência do Pensamento Computacional}

Como já mencionado, na fase de Ideação deste ciclo do DEMULTS-Campo, os estudantes se envolveram no processo de criação de roteiro e storyboards, possibilitando compreender e refletir sobre resolução de problemas em seu cotidiano. Tais instrumentos também orientaram o desenvolvimento de seus artefatos digitais.

Em relação aos roteiros, variados temas foram explorados a partir do contexto dos estudantes, tais como safra/entressafra da cana-de-açúcar e lixo orgânico e inorgânico. Neles, percebe-se uma 
estrutura narrativa, com uma sequência de ideias, personagens e ações. No Quadro 2 é possível identificar a relação entre essas atividades da fase de Ideação e os pilares do pensamento computacional.

\begin{tabular}{l|l}
\hline $\begin{array}{l}\text { Pensamento } \\
\text { Computacional }\end{array}$ & Atividades \\
\hline Decomposição & $\begin{array}{l}\text { Após o roteiro, os estudantes se } \\
\text { envolveram no processo de criação de } \\
\text { storyboards, decompondo-o em cenas que } \\
\text { consideravam principais para imprimir a } \\
\text { ideia central da narrativa. }\end{array}$ \\
\hline $\begin{array}{l}\text { Reconhecimento } \\
\text { de Padrões }\end{array}$ & $\begin{array}{l}\text { Ao dividir o roteiro em cenas, personagens } \\
\text { foram reaproveitados em diferentes } \\
\text { quadros do storyboard, tornando mais fácil } \\
\text { oprocesso. }\end{array}$ \\
\hline Abstração & $\begin{array}{l}\text { Na construção do storyboard, os } \\
\text { estudantes focaram nos elementos-chave } \\
\text { de suas narrativas, ignorando aqueles } \\
\text { considerados irrelevantes para a sua } \\
\text { representação visual. }\end{array}$ \\
\hline Algoritmos & $\begin{array}{l}\text { O roteiro e as cenas ilustradas pelos } \\
\text { estudantes no storyboard têm uma } \\
\text { sequência; com início, meio e fim. }\end{array}$ \\
\hline
\end{tabular}

Quadro 2: Correlação entre atividades de Ideação e o pensamento computacional

No contexto desta pesquisa, as habilidades de PC em foco dialogam com a Educação do Campo, produzindo significados que poderão favorecer o povo do campo. Um dos roteiros produzidos, por exemplo, retrata a rotina de um camponês, cortador de cana-deaçúcar. A narrativa começa em sua casa, acordando nas primeiras horas do dia para ir ao trabalho. Antes de sair, veste uma roupa, pega seu instrumento de corte, o cutelo, e se direciona à parada de ônibus para então se deslocar até uma usina. Ao chegar no local, o gerente questiona quanto ele deseja receber pelo corte de uma quadra $^{1}$ de cana-de-açúcar. Nesse momento a cana já está queimada e o trabalhador do campo inicia o corte. Ao fim, espera a retomada do ônibus para voltar para casa. Passados 15 dias, retorna à usina para receber pelo trabalho feito. De volta para casa, no dia seguinte, o ciclo de trabalho se repete. Então, neste momento, um caminhão e uma carregadeira entram em ação para coletar a cana-de-açúcar cortada.

Tal história se relaciona com o cotidiano do pai de um dos estudantes do projeto e, a partir de sua concepção na etapa de Ideação, pode-se favorecer o desenvolvimento de habilidades do PC vinculadas a artefatos significativos e contextualizados.

Analisando sua construção, é possível identificar que tal narrativa tem uma sequência lógica, sendo dotada de ações do trabalho, que remetem a eventos na programação. Também, é possível identificar estruturas condicionais e de repetição na construção dessa narrativa. A relação entre o fim do trabalho e a retomada para casa, como também a inserção do caminhão e da carregadeira nesse cenário, após a realização da tarefa, trazem elementos que poderiam ser reproduzidos em ambientes de programação, tais como o Scratch, usando estruturas condicionais, como se, senão. A repetição dessa jornada de trabalho a cada 15 dias, também pode ser simulada por meio de estruturas de repetição na programação.

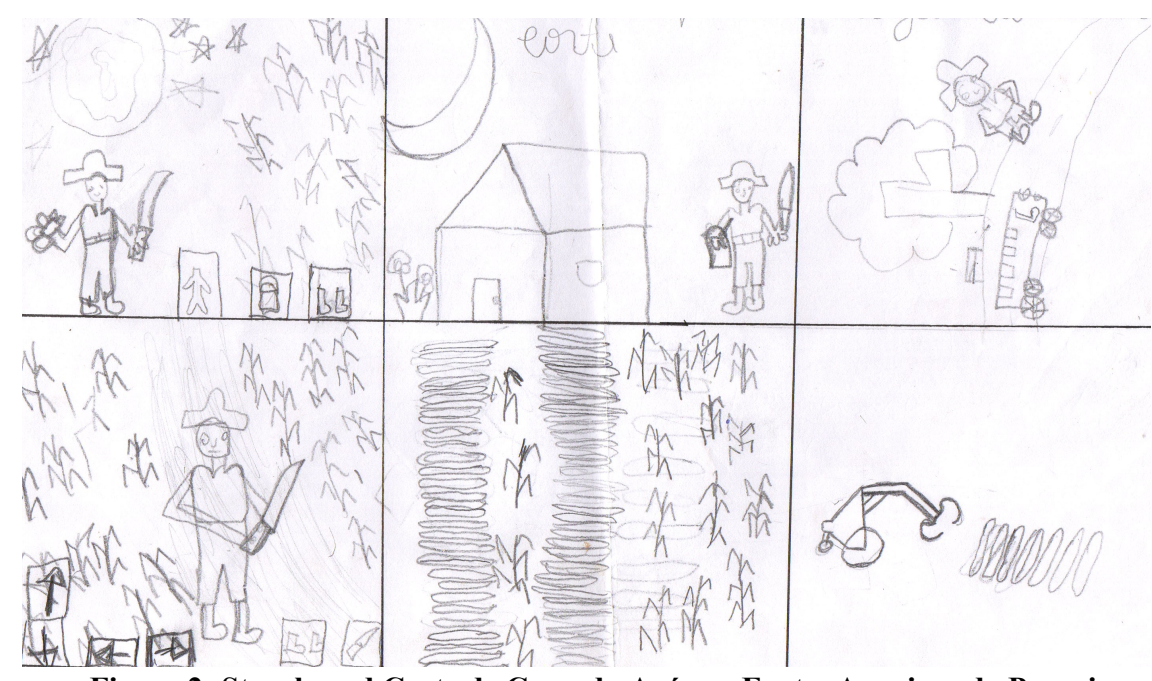

Figura 2: Storyboard Corte de Cana-de-Açúcar. Fonte: Arquivos da Pesquisa

\footnotetext{
${ }^{1}$ Medida de área de plantio de cana-de-açúcar, usada para precificar operações com o caule, como aplicação de agrotóxico e corte. Um dos estudantes relata que este tipo de medida pode ser prejudicial ao cortador, pois o feitor (funcionário da usina que mede
}

a área) pode roubar, já que o instrumento de medida (braça) é impreciso quanto à sua metragem. 
A Figura 2 apresenta o storyboard dessa narrativa. Nele, é possível identificar o personagem principal, como também o ambiente onde as cenas acontecem. O roteiro foi dividido em seis quadros (decomposição), sendo evidenciados seus elementoschave (abstração). O personagem principal aparece em quatro quadros. E, como pode-se observar, os traços definidos no primeiro deles foram reaproveitados nos demais, otimizando a tarefa de criação de storyboard (reconhecimento de padrões). Por fim, as cenas principais são apresentadas em uma sequência lógica (algoritmos), conforme previsto na narrativa.

A natureza da metodologia DEMULTS dialoga com perspectivas situada e crítica do pensamento computacional. Nesse sentido, cabe enfatizar a relação cada vez mais horizontal que foi construída pelos pesquisadores, professoras, técnicos agrícolas e estudantes na discussão sobre atividades cotidianas exploradas na região, as quais emergiram no processo de desenvolvimento dos artefatos digitais produzidos. Dentre os elementos contemplados nessas discussões pode-se citar: o uso de herbicida e agrotóxicos, as variedades de cana-de-açúcar, a utilização de equipamentos de proteção individual, a valorização do trabalhador, o processo de corte e os problemas de saúde decorrentes desse trabalho.

Após a composição da narrativa em análise, os estudantes produziram, com lápis e papel, diálogos entre personagens em torno do corte de cana-de-açúcar, os quais posteriormente seriam aportados em seus projetos Scratch. Ao apresentar a um dos pesquisadores (D) a proposta de diálogo, um dos estudantes (E) foi provocado a discutir e refletir sobre as relações de trabalho praticadas em sua região. Em especial, o valor pago ao cortador de cana e o valor mínimo previsto em lei são discutidos, como ilustra o diálogo a seguir:

1. D ((sentando)) É o trabalhador conversando com o gerente...

2. E ((com o olhar fixo para o roteiro escrito em papel)) [[

3. EXATAMENTE! Aí ele chega lá na mina:

4. E - Quando eu ganho?

5. E - Você ganhará ::em uma quadra onze reais. Aceita o

6. serviço?

7. E ((altera o ritmo da voz para simular o novo personagem))

8. - Não. Onze reais é muito pouco!

9. $\mathrm{E}-\mathrm{E}$ você quer ganhar:: quanto?

10. $\mathrm{E}-$ Bom:: de:: trinta e dois a trinta e cinco reais.

11. E- ((vira a folha do roteiro)) Você quer me quebrar?

12. E - Bom: : na verdade era pra o cortador de::

13. ganhar muito mais

14. E - Tá bom, eu deixo por trinta e cinco reais.

15. E Fechado? ((olha para D))

16. D Tá:: vê só:: ((coloca a mão sobre o ombro de E))

17. E ((cruza as mãos com os cotovelos sobre a mesa))

18. D Na prática hoje ele ganha trinta cinco. Né isso?

19. E ((bebe água)) Uhuum
20. D Né?

21. E ((cruza as mãos com os cotovelos sobre a mesa )) Hum!

22. D Né?

23. E É, rapaz! ((cruza os braços))

24. D Certo É justo??

25. E Não ((com os braços cruzados, balança a cabeça

26. negativamente))

27. E Quer dizer, a lei:: ((gesticula com as mãos explicando))

28. que é (incompreensível) era pra ele ganhar trinta em cinco, né?

29. Mai:: ((toca as maões uma vez, como num movimento de

30. aplauso; cruza os dedos; gesticula, explicando) era pra ganhar

31. muito mais...

/.../

No episódio transcrito, após o estudante E apresentar as falas de seus personagens ao pesquisador $\mathrm{D}$, inicia-se uma discussão quanto ao valor pago a um cortador de cana-de-açúcar, personagem principal do jogo. E, na linha 27, o estudante dá indícios de que conhece as leis aplicadas ao trabalho explorado em seu cotidiano, embora demonstre não concordar, quanto ao valor pago pelo corte de uma quadra de cana-de-açúcar (linha 25).

A cena continua com a chegada de dois técnicos agrícolas, pontuando aspectos legais quanto ao trabalho com o corte de canade-açúcar; tendo como desfecho a busca, na Internet, das leis que amparam tal atividade, privilegiando, assim, a construção de significados e sentidos, a partir da comunidade de prática.

A Figura 3 ilustra a cena na qual fazem parte um estudante (E), um dos pesquisadores (D) - que estão sentados - e os técnicos agrícolas, em pé. $\mathrm{Na}$ imagem também é possível identificar os artefatos e tecnologias que tornam possíveis a interação entre eles. Sobre a mesa estão os papéis com os diálogos criados pelo estudante que provocaram a discussão em questão. Além disso, dois artefatos tecnológicos - o celular e o computador - são introduzidos na interação vislumbrando uma compreensão e reflexão mais profunda quanto às leis do trabalho. Um ponto que carente atenção nessa cena é o uso do celular, pelo estudante, mesmo havendo a projeção da temática em discussão na tela do computador, a partir da qual um dos técnicos busca explicar seu entendimento. Este fato sugere o interesse de E pelo tema, se amparando não apenas nas relações sociais provindas pela comunidade de prática, mas também nos artefatos a essa associados para a construção de seu conhecimento.

Ancorado pelo pensamento computacional crítico, esse diálogo se apresenta como oportunidade de estabelecer uma relação entre a formação desses sujeitos com sua realidade social e econômica; questionando, analisando e produzindo sentidos sobre essa realidade. Essa perspectiva se relaciona com um movimento contra-hegemônico que atribui à zona rural um contexto com múltiplas dimensões da vida, não se limitando a uma área produtora de mercadorias. 


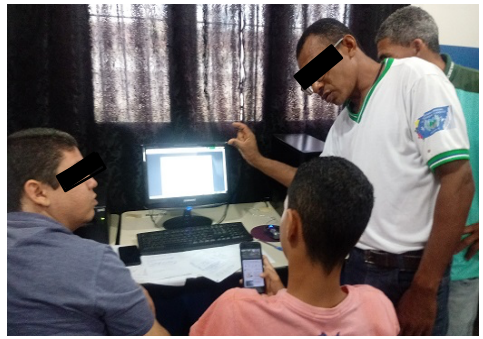

Figura 3: Membros da Comunidade de Prática. Fonte: Arquivos da Pesquisa

De forma complementar, ao se considerar as situaçõesproblema discutidas, as quais foram aportadas em artefatos digitais educacionais direcionados a um público campesino do qual fazem parte os estudantes, o alcance formativo é ampliado. Isso pode fortalecer a atuação desses sujeitos na comunidade, constituindo-se como uma condição de sua transformação. A computação, nesse cenário, aparece como um mecanismo para expressão do modo de vida camponês, materializado em jogos digitais e aplicativos.

Brennan e Resnick [12] já enfatizavam que as pessoas estão cercadas por mídias interativas, mas que na maioria das experiências são consumidores. A exploração do pensamento computacional, nesse contexto, proporciona algo mais do que consumir. Os estudantes podem usar a computação para projetar, autoexpressar e compartilhar suas ideias por meio dessas mídias. Na fase de Produção do DEMULTS-Campo, essa perspectiva foi registrada, e o diálogo que segue aponta para o entusiasmo de um dos estudantes (E) na conversa com uma das pesquisadoras $(\mathrm{F})$ ao visualizar o resultado da programação de seu projeto Scratch, no qual os personagens se comunicavam a partir da problemática anteriormente discutida:

1. E ((olha para o computador e depois para $\mathrm{F}$, passa uma

2. das mãos no queixo)) Olha praí que banaca:

3. E Pra mim era (incompreensível)

4. F ((em pé)) Seu joguinho tá tomando forma, hein?

5. E ((se afasta do computador, encostando a costas na

6. cadeira) Gostei.. sinceramente, vi:: Agora vou

7. (incompreensível)

/.../

Neste momento, as discussões e reflexões que permearam o projeto ganharam um formato digital, e o registro transcrito enfatiza a relação do estudante com o artefato criado, vinculada de condições para a emergência do PC em territórios rurais..

\subsection{O Artefato Resultante}

Neste ciclo do DEMULTS-Campo, foram produzidos cinco jogos e um aplicativo móvel, com os temas: i) período da safra e da entressafra de cana-de-açúcar; ii) coleta seletiva de resíduos; e iii) horta agroecológica.

No presente artigo, os dados emergiram do processo de desenvolvimento do jogo sobre cana-de-açúcar. O resultado do protótipo construído com os estudantes pode ser visto na Figura 4.
Nela se pode ver o diálogo do trabalhador (representado pela garota) com o gerente da usina. Os personagens e cenários usados foram disponibilizados pelo próprio Scratch e ainda serão atualizados para representar os esboços dos novatos de design.

No segundo quadro da imagem é possível ver um retângulo verde representando o facão usado para cortar a cana. Nesse momento, o jogador clica nele e o objeto passa a seguir a seta do mouse do jogador. Ao encostar na parte debaixo da cana, ela é cortada; e após isso é preciso cortar a sua parte cima (olho), clicando sobre a parte verde. Então, a cana é colocada em posição horizontal no chão para, ao término do processo, ser levada à usina pelo coletor. Uma função que ainda não foi desenvolvida no Scratch envolve o trabalhador ensinando sua filha sobre plantio orgânico.
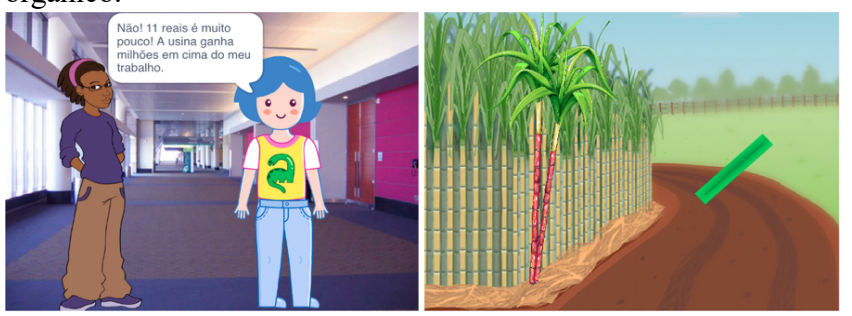

Figura 4: Protótipo do jogo sobre safra de cana-de-açúcar

Regularidades nas ações que favorecem a emergência do PC, como exemplificadas neste artigo, foram encontradas nos processos interacionais referentes aos cinco artefatos. No entanto, os motivos das atividades, especificamente objetivados pelas interfaces distintas desses artefatos, parecem favorecer, de modo também diverso, a ênfase com que algumas habilidades computacionais surgem e se desenvolvem nas situações. Faz-se necessário compreender essas emergências distintas, em trabalhos futuros, integrando a discussão da Educação do Campo às configurações contextuais do DEMULTS, em seus aspectos práticos de programação e design, na etapa de Produção.

\section{Considerações Finais}

No Brasil, uma problemática vivenciada por adolescentes do campo, em sua educação formal, diz respeito à ausência de contextualização dos conteúdos curriculares para territórios rurais, a qual é minimizada pela Educação do Campo com suas diretrizes específicas. Nesse contexto, dada a necessidade do desenvolvimento do pensamento computacional para os cidadãos da sociedade contemporânea, esta pesquisa buscou favorecer a emergência do PC em territórios rurais, a partir da construção de artefatos digitais com estudantes do campo, privilegiando a produção de sentidos para a realidade campesina.

Com base em uma abordagem histórico-cultural em psicologia, neste artigo verificou-se a emergência do PC a partir das relações dialógicas evidenciadas durante o desenvolvimento de artefatos digitais pelos estudantes; sendo percebidos conceitos computacionais em diferentes etapas da metodologia DEMULTS. A análise se debruçou, especialmente, no processo de desenvolvimento de um jogo sobre cana-de-açúcar, sendo identificada a emergência do PC em fases como Ideação e 
Produção. Os resultados discutidos foram oriundos de diferentes fontes de dados, como fotos, episódios videográficos e desenhos feitos pelos estudantes; apoiando a sua validade para o contexto observado.

Ao longo dos ciclos do DEMULTS, intencionalmente fomos nos afastando de abordagens mais diretivas de ensinoaprendizagem, como geralmente acontecem em cursos de formação ou capacitação, e nos aproximando da aprendizagem na/pela prática, com as atividades de desenvolvimento dos produtos "em si", sendo o foco do processo de ensino-aprendizagem. Desse modo, a aprendizagem sobre Scratch e App Inventor ocorre nas situações reais de resolução de problemas, as quais emergem nas $\mathrm{CoP}$, da interação entre experts (pesquisadores) e novatos (estudantes), durante o processo de desenvolvimento dos artefatos.

Dada a abordagem adotada na pesquisa - um estudo de caso, com as especificidades de uma pesquisa-ação, em que se procura considerar todos os aspectos contextuais que compõem as situações - pôde-se favorecer a educação do campo. E isto foi oportunizado por meio da discussão e reflexão de temas e produção de artefatos vinculados a esse contexto. Também, a pesquisa sobre PC foi favorecida, ao evidenciar que perspectivas situada e crítica podem promover práticas educativas no campo.

Um vez que a experiência vivenciada possibilitou o desenvolvimento de seis artefatos digitais, trabalhos futuros devem se debruçar sobre sua análise, considerando a influência dos seus tipos (jogos e aplicativo), como também dos seus temas para a emergência do PC, observando se as regularidades identificadas na análise do jogo sobre cana-de-açúcar são também neles encontradas.

Outra ação futura pretendida, interrompida pela pandemia da COVID-19, diz respeito à identificação da percepção dos estudantes sobre a experiência vivenciada. Também, almeja-se realizar testes dos artefatos produzidos; os quais são direcionados ao público campesino, buscando identificar pontos de melhoria, como também ampliar o alcance formativo do PC a partir de perspectivas situada e crítica.

\section{REFERÊNCIAS}

[1 A. Raabe; N. E. R. Couto; P. Blikstein. 2020. Diferentes abordagens para a computação na educação básica. In: A. Raabe, A. F. Zorzo, P. Blikstein (Org.) Computação na educação básica: fundamentos e experiências. Porto Alegre: Penso, 2020.

[2] BBC. Introduction to computational thinking. 2015. Disponível em $<$ https://www.bbc.co.uk/bitesize/guides/zp92mp3/revision/1>. Acesso em 15 jan. 2020.

[3] B. Jordan; A. Henderson. 1995. "Interaction Analysis: Foundations and Practice." The Journal of the Learning Sciences, 4(1): 39-103.

[4] B. M. Fernandes. Os campos da Pesquisa em Educação do Campo: espaço e território como categorias essenciais. In: M. C. Molina (Org.). Educação do Campo e Pesquisa: questões para reflexão. Ministério do Desenvolvimento Agrário: Brasília, 2006. p.27-39.

[5] B. T. Fasy; Stacey A. Hancock; Barbara Z. Komlos; B. Kristiansen; S. Micka; A. S. Theobold (2020). Bring the Page to Life: Engaging Rural Students in Computer Science Using Alice. In: Proceedings of the 2020 ACM Conference on Innovation and Technology in Computer Science Education, 110-116.

[6] C. E. F. dos Santos; C. Paludo, R. B. C. de Oliveira. Concepção de educação do campo. In: C. N. Z. Taffarel; C. de L. Santos Júnior; M. O. Escobar, (orgs). Cadernos didáticos sobre educação no campo. Universidade Federal da Bahia, Salvador: EDITORA, 2010.

[7] E. C. Dillon, Jr.; M. Anderson-Herzog. (2015). Exposing Rural AfricanAmerican Students to Computer Science as a Career Choice Using Robots. In: Research in Equity and Sustained Participation in Engineering, Computing, and Technology , IEEE, 1-1.
[8] E. Wenger. Communities of practice and social learning systems. Organisation, v.7, n.2, p. 225-246, 2000.

[9] F. Pires; J. C. Duarte; L. Pessoa; K. S. Pereira; R. Ferreira; R. de Freitas. (2018). Uma análise cognitiva entre a emergência de padrões em narrativas infantis e elementos do Pensamento Computacional. In: Anais do XXIX Simpósio Brasileiro de Informática na Educação, 1193-1202.

[10] J. Lave; E. Wenger. Situated learning: Legitimate peripheral participation. New York, Cambridge University Press, 1991.

[11] J. M. Wing. 2006. Computational thinking. Communications of the ACM, v. 49, n. 3, 33-35.

[12] K. Brennan; M. Resnick. 2012. New frameworks for studying and assessing the development of computational thinking. In Proceedings of The 2012 Annual Meeting of the American Educational Research Association, Vancouver, Canada, $1-25$.

[13] M. C. Molina. (Org.). Educação do Campo e Pesquisa: questões para reflexão. Ministério do Desenvolvimento Agrário. Brasília: 2006.

[14] M. Tissenbaum, J. Sheldon, H. Abelson. 2019. From Computational Thinking to Computational Action. Communications of the ACM, v.62, n.3. DOI: $10.1145 / 3265747$.

[15] R. M. Vicari; Á. Moreira; P. B. Menezes (2018). Pensamento Computacional: Revisão Bibliográfica. Projeto UFRGS/MEC Avaliação de Tecnologias Educacionais.

[16] R. S. Caldart. Por uma educação do campo: traços de uma identidade em construção. In: Educação do campo: identidade e políticas públicas- Caderno 4. Brasília: Articulação Nacional "Por Uma Educação Do Campo", 2002.

[17] S. da S. Vieira; M. Sabbatini. (2020). Cultura Maker na Educação através do Scratch visando o desenvolvimento do pensamento computacional dos estudantes do $5^{\circ}$ ano da Escola Base Rural da Cidade de Olinda-PE. Revista Docência e Cibercultura, 4(2), 43-66.

[18] S. Papert; Cynthia Solomon. 1971. Twenty things to do with a Computer. Educational Technology Magazine. Disponivel em: http://www.stager.org/articles/twentythings.pdf

[19] Y. Kafai; C. Proctor; D. Lui. (2019) From Theory Bias to Theory Dialogue: Embracing Cognitive, Situated, and Critical Framings of Computational Thinking in K-12 CS Education. In: Proceedings of the 2019 ACM Conference on International Computing Education Research. 101-109. 